\title{
Smart Orchard Irrigation System
}

\author{
Jucilene de Medeiros Siqueira \\ CAPES \\ CSF Program, Brazil
}

jucilene.m.siqueira@gmail.com

\author{
José Machado da Silva \\ INESC TEC, Faculdade de Engenharia, \\ Universidade do Porto, \\ Porto, Portugal \\ jms@fe.up.pt
}

\author{
Teresa Afonso do Paço \\ LEAF, Instituto Superior de Agronomia, \\ Universidade de Lisboa \\ Lisboa, Portugal \\ tapaco@isa.ulisboa.pt
}

\begin{abstract}
The present work addresses the development of a smart orchard irrigation system (SOIS) that performs the estimation of orchard evapotranspiration and the estimation of the soil salinization risk. Measurements of heat transfer are made to compute tree transpiration rate and soil water evaporation. The soil electrical conductivity is measured to compute the soil salinization risk. An inferential fuzzy algorithm is used to process data. This paper describes the physical principles underlining these estimations, the architecture of the data acquisition interface, and the construction and characterization of the probes used to perform the temperature measurements. The preliminary results shown here address the experimental evaluation of the performance of the probes inserted in the trees. Relative measurements with a precision of $0.2^{\circ} \mathrm{C}$ were obtained which are in agreement with the minimum required for these applications.
\end{abstract}

Keywords - evapotranspiration measurements, precision agriculture, smart irrigation.

\section{INTRODUCTION}

The issues concerning to the efficient use of water in agriculture are at forefront of contemporary societal problems. Water scarcity has been detected both in arid and susceptible to drought areas, as well as in regions of abundant rainfall. In this regard, several studies point out solutions to cope with insufficiency of water, investigating the ability for an improved quality and reduced quantity use of water, while preventing new environmental impacts and the reduction of farming productivity $[3,12,13]$.

It is known that irrigation systems can be controlled after evaluation of the biophysical parameters and variables related to the hydric and heat transference inside of the vadose zone in irrigated crop, among plants, soil and atmosphere $[1,2,11]$.

Multifunctional devices designed for mass and heat transfer measurements have received increased attention over the past few years. In fact, several benefits are achieved by combining these measurements. First, by measuring several parameters at the same time and place, the coupling of related transport properties are determined in concert, thereby allowing for examining the nature of their interdependency, such as for the coupled transport of water and solute, and water and heat. Second, by using the same instrument for various measurements within approximately the same system volume at about the same time, the need to interpolate different measurement types in space and time is largely eliminated [10].

An efficient watering in agriculture requires that the control instruments for water management determine qualitatively and quantitatively the plant transpiration, soil evaporation rate and the salt content in the aqueous phase of the soil. As a result, the quality / quantity ratio factor of the irrigation water could relate to the quantity and quality of water and salts in the soil, corroborating to the soil and water degradation risk control.

Evapotranspiration (ET) and soil salinization (SS) are not easy to evaluate and control. Specific devices and accurate measurements of various physical parameters and the soil water balance are required to estimate evapotranspiration rates. The instruments used in these applications are often expensive and demanding in terms of measurement accuracy and personnel knowledge and abilities, which make them not fully suitable for use in disadvantaged regions. Besides, the methods being used are inappropriate for routine measurements. However, they remain useful for the estimation of ET after indirect methods [2] and for monitoring the SS process in water scarcity regions [14]. Such estimations can be carried out and evaluated by extensive analyses and data processing. However, in order to provide for a lower cost, automatic and real-time systematized operation, data acquisition devices and processing methods specifically designed for this purpose are required. A simple approach is using programmable logic controllers (PLC) associated with computing and sensor and actuator devices to, in real time, automatically and in a differentiated way, process and analyse the set of measurements required to control the quality and quantity of irrigation water, as well as to infer about the risk of salinization.

The work presented herein addresses principles and guidelines to validate the data acquisition and measurement capabilities of a smart orchard irrigation system (SOIS) to estimate ET and SS risk. It is also shown how sap flow measurements are implemented. Next section presents the SOIS architecture. Section III presents the theoretical 
principles underlining the ET and SS estimation processes. Section IV shows a short description of the application specific sensing circuits and data acquisition features. Section V describes the methodology of the data processing algorithm being used in the sap flow estimation. Section VI presents preliminary experimental results obtained in the laboratory and in the field. Section VII highlights the main conclusions.

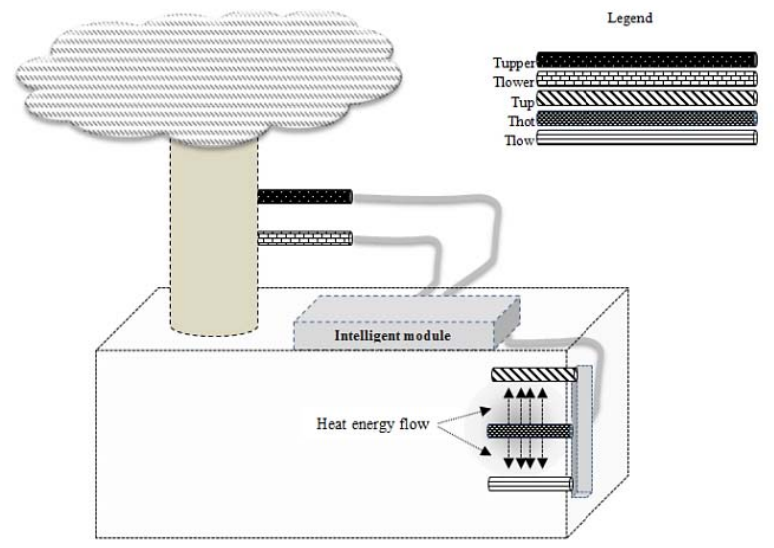

Fig.1 - Placement of the SOIS system in the field.

\section{THE SOIS SYSTEM}

The SOIS system consists of two modules: the data processing module (DPM) and the data acquisition module (DAM). The processing module functions as a logic controller. It is based on an Atmega2560 Arduino board [8]. The controlling process relies on a fuzzy algorithm, which is responsible for calibration, control and monitoring of the information received from the sensor array. It drives the system after processing data and measurements, as well as, determining data collection times and intervals. It also defines and qualifies parameters that describe relationships in each event [15].

The data acquisition module comprises a custom designed board which provides the interface between the Arduino I/O and an array of actuator and sensor probes to be placed in the tree and soil (Fig. 1).

The orchard ET rate is obtained after estimating the sap flow in a tree trunk and the soil evaporation level and characteristics are obtained from measurements of heat flux density, heat storage at the soil surface, and soil conductivity which is measured with two simple probe terminals.

The DAM was then designed to perform these measurements. For sap flow measurements two temperature probes separated by $10 \mathrm{~cm}$ in the vertical $\left(T_{\text {upper }}\right.$ and $T_{\text {lower }}$ in Fig. 1) are used. The $T_{\text {upper }}$ probe contains a heating element and a thermistor (Fig. 2) and the $\mathrm{T}_{\text {lower }}$ probe only one thermistor. Typically, the maximum temperature difference to be measured is about $10{ }^{\circ} \mathrm{C}$. Commercial systems for these applications only provide a temperature difference measurement. The system being proposed provides also the two absolute temperatures allowing thus for a more accurate observation of the process.

For the measurements in the soil a set of three probes $\left(\mathrm{T}_{\text {up }}, \mathrm{T}_{\text {hot }}\right.$ and $\left.\mathrm{T}_{\text {low }}\right)$ mounted in a comb like disposition is used (Fig.1). The outer probes $\left(\mathrm{T}_{\text {up }}\right.$ and $\left.\mathrm{T}_{\text {low }}\right)$ comprise only thermistors, while the central one $\left(\mathrm{T}_{\text {hot }}\right)$ is $\mathrm{T}_{\text {upper }}$ like. The spacing between the $\mathrm{T}_{\text {up }}, \mathrm{T}_{\text {hot }}$ and $\mathrm{T}_{\text {low }}$ probes is about $6 \mathrm{~mm}$.
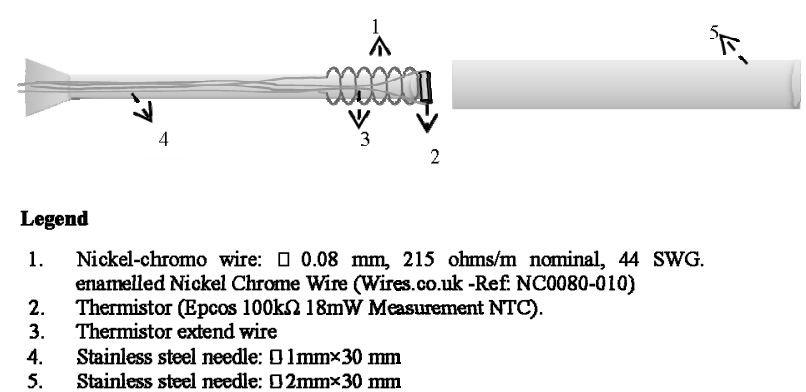

Fig.2 - Schematic of the heating and sensing probe.

All probes were made with a stainless steel tubing 19 Gauge x $1 \frac{1 / 2}{2}$ " $40 \mathrm{~mm}$ Luer-Lock. The thermistors are the Epcos $100 \mathrm{k} \Omega 18 \mathrm{~mW}$ NTC, $1 \%$ tolerance, devices. The heating elements are made with a nominal $215 \Omega \cdot \mathrm{m}$ resistivity, 44 SWG enamelled Nickel-Chrome wire.

The sap flow and the soil water evaporation rate are inferred after measuring temperature differences observed between the heated point $-\mathrm{T}_{\text {upper }}$ in the trunk and $\mathrm{T}_{\text {hot }}$ in the soil - and the neighbour points $-\mathrm{T}_{\text {lower }}$ in the trunk and $\mathrm{T}_{\text {up }}$ and $\mathrm{T}_{\text {low }}$ in the soil.

\section{Underlying PhysiCAL PHENOMENA}

The SOIS system relies on custom algorithms to estimate the transpiration, soil evaporation and soil degradation risk, including the observation of environmental parameters for sap flow measurement calibration according to the Granier method [6]. As the operating conditions change, namely due to environmental changes and soil conditions, the parameters of the controlling laws change as well; therefore the system requires that preliminary calibrations are performed periodically automatically.

\section{A. Transpiration estimation}

The evaluation of tree transpiration is made after heating slightly a point inside of the tree trunk (xylem) by using a heating probe, and measuring the temperature variation observed in a point about $10 \mathrm{~cm}$ below that heating spot (Fig. 1). Transpiration is inferred after relating the heat transfer with the sap flow. For this purpose two temperature sensors are used to measure the difference of temperatures $\Delta \mathrm{T}\left[{ }^{\circ} \mathrm{C}\right]$ at the heated and the unheated observation points. The flux index $\mathrm{k}_{G}$ is obtained with the empirical Granier equation (Eq. 1). 


$$
k_{G}=\frac{\Delta T_{\max }-\Delta T}{\Delta T}
$$

where $\Delta \mathrm{T}_{\max }\left[{ }^{\circ} \mathrm{C}\right]$ is the maximum value of $\Delta \mathrm{T}$ on a daily course and which is related to the minimum or null sap flux rate for that specific day. The flux is calculated from $\mathrm{k}_{G}$ using a relationship admitted to be species independent [6] and based on empirical calibrations (Eq.2),

$$
u=118.99 \times 10^{-6} k_{G}^{1.231}
$$

where $u\left[\mathrm{~m}^{3} \mathrm{~m}^{-2} \mathrm{~s}^{-1}\right]$ is the sap flux density. The sap flux $F$ $\left[\mathrm{m}^{3} \mathrm{~s}^{-1}\right]$ can be calculated from (Eq.3):

$$
F=u \times A
$$

where $A\left[\mathrm{~m}^{2}\right]$ is the area of the conducting xylem section.

Within the system under development this estimation is completely automatable, requiring a time $\mathrm{t}[\mathrm{s}]$ indexed capturing of the temperatures of both probes $\mathrm{T}_{\text {upper }}\left[\mathrm{C}^{\circ}\right]$ and $\mathrm{T}_{\text {lower }}\left[\mathrm{C}^{\circ}\right]$, after switching on and off the heater and then performing the data processing and inferential control.

\section{B. Soil evaporation estimation}

The estimation of soil water evaporation can be based on the sensible heat balance of a soil layer [6]. A sensible heat balance is used to determine the amount of latent heat involved with vaporization of soil water following (Eq.4) [5]:

$$
G_{u p}-G_{l o w}-S=L E
$$

where $\mathrm{G}_{\text {up }}\left[\mathrm{W} \mathrm{m}^{-2}\right]$ and $\mathrm{G}_{\text {low }}\left[\mathrm{W} \mathrm{m}^{-2}\right]$ are soil sensible heat fluxes at upper and lower depths (separated by a distance $\Delta \mathrm{z}$ ), respectively; $\mathrm{S}\left[\mathrm{W} \mathrm{m}^{-2}\right]$ is the change in soil sensible heat storage between upper and lower depths; $\mathrm{L}\left[\mathrm{J} \mathrm{m}^{-3}\right]$ is the latent heat of vaporization and $\mathrm{E}\left[\mathrm{m} \mathrm{s}^{-1}\right]$ is evaporation. Using measurements of the soil thermal conductivity $k$ [W $\left.\mathrm{m}^{-1}{ }^{\circ} \mathrm{C}^{-1}\right]$ and the temperature gradient $\Delta \mathrm{T} / \Delta \mathrm{z}\left[{ }^{\circ} \mathrm{C} \mathrm{m}^{-1}\right]$, values for $\mathrm{G}$ can be determined from Fourier's law (Eq. 5) by determining $\mathrm{S}$ from measured temperature $\mathrm{T}\left[{ }^{\circ} \mathrm{C}\right]$ and soil volumetric heat capacity $\mathrm{C} v\left[\mathrm{~J} \mathrm{~m}^{-3}{ }^{\circ} \mathrm{C}^{-1}\right]$ (Eq.6) [7].

$$
G=-k \Delta T / \Delta z
$$

$$
S=C v\left(\frac{\Delta T}{\Delta t}\right)(\Delta z)
$$

The residual from the sensible heat balance provided by the left-hand side of equation (4) is attributed to LE, which cannot be measured directly. Values for L can be calculated from [4]

$$
L=2.49463 \times 10^{9}-2.247 \times 10^{6} T_{m}
$$

where $\mathrm{T}_{\mathrm{m}}\left[{ }^{\circ} \mathrm{C}\right]$ corresponds to the mean temperature for a given depth layer and time step. Having values for $\mathrm{G}, \mathrm{S}$, and $\mathrm{L}$ it is possible to calculate $\mathrm{E}$ from Eq. (4).

\section{Warning of soil degradation risk}

The evaluation of the soil degradation risk is inferred from the soil apparent electrical conductivity EC $a$ [dS m$\left.~^{-1}\right]$ and soil moisture $\theta\left[\mathrm{m}^{3} \mathrm{~m}^{-3}\right]$ measurements in the temporal domain. The linear function given by Eq. (8) is used to monitor the salinity indicator $\beta_{\theta}\left[\mathrm{m}^{3} \mathrm{~m}^{-3}\right]$.

$$
\begin{aligned}
& \beta_{\theta}=\theta_{t}-\alpha_{E C} \times E C a_{t} \\
& \alpha_{E C}=\frac{\theta_{F C}-\theta_{W P}}{E C a_{F C}-E C a_{W P}}
\end{aligned}
$$

where $\alpha_{\mathrm{EC}}\left[\mathrm{m} \mathrm{dS}^{-1}\right]$ is the evaporation coefficient, $\theta_{\mathrm{FC}}$ is the soil field capacity, $\theta_{\mathrm{PM}}$ is the soil wilting point, $\mathrm{EC} a_{\mathrm{FC}}$ and $\mathrm{EC} a_{\mathrm{WP}}$ are the soil apparent electric conductivity while the soil is in the field capacity and wilting point, respectively.

The $\alpha_{\mathrm{EC}}$ value (Eq.9) is a constant and is related to the soil properties. However, $\beta_{\theta}$ fluctuates linearly according to the water and salts quantities in the soil. The parameter $\beta_{\theta r e f}$ (Eq.10) is a reference determined in the initial time of the scheduled irrigation,

$$
\beta_{\theta_{r e f}}=\theta_{t 0}-\alpha_{E C} \times E C a_{t 0}
$$

where $\theta_{\mathrm{t} 0}$ and $\mathrm{EC} a_{\mathrm{t} 0}$ are, respectively, the soil moisture and the soil apparent electrical conductivity measurements in the initial time.

The processing data works with the $\beta_{\theta r e f}$ constant, computed in the onset of the scheduled irrigation and the $\theta_{t}$ variable, supplied via inputs per time interval. Eq. (8) is computed by insertion of the $\beta_{\theta}$ values and the evaluation of the soil degradation risk by an automatic fuzzy reasoning (AFR).

AFR is based on a fuzzification procedure, whose input values are converted to labelled values associated to a degree of membership. The fuzzification technique comprises the universe of discourse (UD) of the variable $\beta_{\theta}$ in the interval [high lixiviation risk; high salinization risk]. The UD is divided in $n_{f r}$ fuzzy regions, which are overlapped sets and quantified by $n_{f r}=2 \mathrm{~N}+1$, where $\mathrm{N}$ is an adequate numerical choice that ensures an odd number for $n_{f r}$, with a central region, i.e, $\beta_{\text {eref. }}$ The accuracy of the algorithm can be regulated through an adequate choice of $\mathrm{N}$, since larger values generally imply higher accuracy levels. However, it increases the computational effort.

As the relation between $\mathrm{EC} a$ and $\theta_{t}$ values is a linear function in that UD [14], the simple triangular membership function (FS) is adopted and easily computed as:

$$
F S_{j}\left(x_{i}\right)=\left\{\begin{array}{lc}
0 & x_{i}<a_{j} \\
\left(x_{i}-a_{j}\right) /\left(b_{j}-a_{j}\right) & a_{j} \leq x_{i} \leq b_{j} \\
\left.c_{j}-x_{i}\right) /\left(c_{j}-b_{j}\right) & b_{j} \leq x_{i} \leq c_{j} \\
0 & x_{i}>c_{j}
\end{array}\right.
$$

where $a_{j}$ and $c_{j}$ are defined by a lower limit of membership with $a_{j}<c_{j}, b_{j}$ is defined by an upper limit of membership, and $x_{i}$ is the fuzzification input value, e.g., $\theta_{t}$ values. The parameters $a_{j}, b_{j}$ and $c_{j}$ of a triangular membership function for the $j_{t h}$ fuzzy set $\left(\mathrm{FS}_{\mathrm{j}}\right)$ can be calculated by:

$$
b_{I}=2 \beta_{\theta \mathrm{ref}} /\left(n_{f r}-1\right), \ldots, b n_{f r}=\mathrm{b} n_{f r-1}+2 \beta_{\theta \mathrm{ref}} /\left(n_{f r}-1\right)
$$




$$
\begin{aligned}
& a_{i}=b_{i}-2 \beta_{\theta \mathrm{ref}} /\left(n_{f r}-1\right) \\
& c_{i}=b_{i}+2 \beta_{\theta \mathrm{ref}} /\left(n_{f r}-1\right)
\end{aligned}
$$

with the domain interval of UD $\left[0 ; 2 \beta_{\theta \text { ref }}\right]$ divided in $\left(n_{f r}-1\right)$ equal regions. Such information and the $\mathrm{N}$ value should be included in the knowledge base.

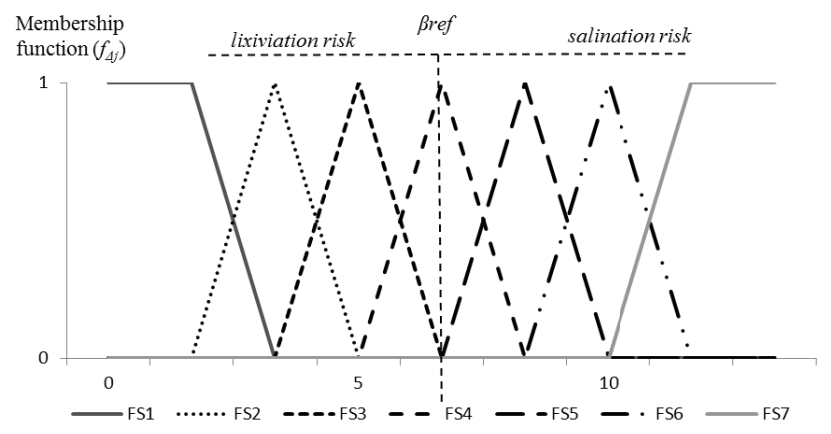

Fig.3 : Fuzzy set of soil degradation risk control.

For example, inserting the values $\mathrm{N}=2$ and $\mathrm{UD}=[0$; $10]$ in the system creates 7 fuzzy sets (Fig. 3). The system will classify the $\beta_{\theta}$ computed values and compare it with the value $\beta_{\theta_{\text {ref }}}$ obtained in onset of the scheduled irrigation.

\section{HeAting CONTROLler AND DATA ACQUisition}

Figure 4 shows the schematics of the thermistors interface and heating circuits. In an orchard there is one data acquisition and control module per tree (Fig. 1). The temperature measurements are performed after capturing the voltage provided by a voltage divider made with a constant resistor and the thermistor. Each module captures the analogue voltages provided by four thermistor circuits using a single analogue input (AI). Digital outputs are used to select the thermistor circuit voltage to be captured and to switch on/off the regulated voltage sources. The thermistor voltages are also captured to provide feedback for calibration purposes.

Once the range of temperatures involved is not large and the temperature differences to be detected are small $\left(\leq 1^{\circ} \mathrm{C}\right)$ the thermistors non-linear characteristic is not critical in this application. Considering the temperature is read as a voltage given by $V_{T 1}=5 \times R_{1} /\left(R_{T 1}+R_{1}\right)$, the sensitivity of the temperature measurement is proportional to $d V_{T 1} / d T=-5 \times \frac{R_{1}}{\left(R_{T 1}+R_{1}\right)^{2}} \frac{\partial R_{T}}{\partial T} \approx \approx 56.2 \mathrm{mV} /{ }^{\circ} \mathrm{C}$, i.e., $11.4 \mathrm{mV}$ per $0.2{ }^{\circ} \mathrm{C}$, for a $5 \mathrm{~V}$ voltage source. The 10 -bit ADC of the $\mu$ controller ensures a resolution of $\mathrm{V}_{\mathrm{LSB}}=4.88 \mathrm{mV}$. The thermal noise of the resistive voltage divider generates (worst case) an rms voltage of $40 \mathrm{nV} / \sqrt{\mathrm{Hz}}$.

The tree heater resistance is supplied by a digitally controlled current source of $\sim 0.1$ A to provide a power of $0.2 \mathrm{~W}$. The soil heater resistance is supplied with a controlled current source of $\sim 0.56$ A to provide a power of $3.6 \mathrm{~W}$.
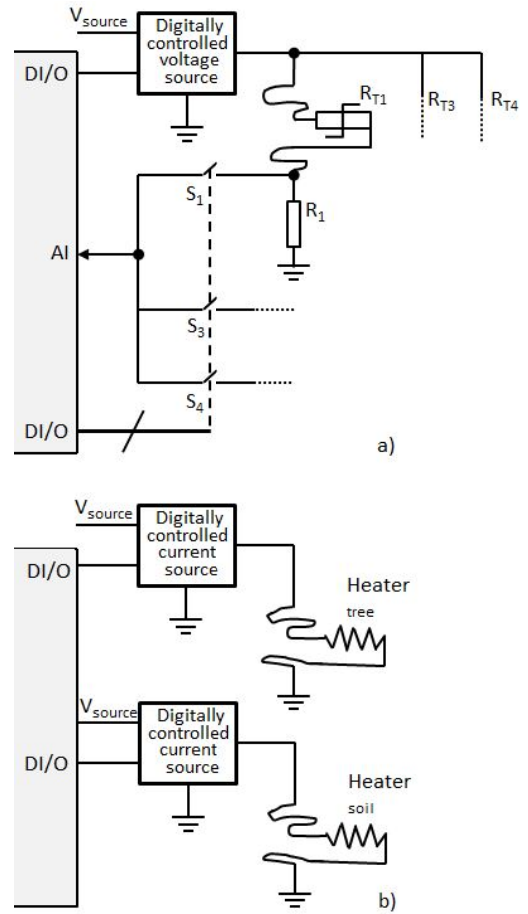

Fig.4- Schematic of the a) thermistors interface and b) heater circuits.

\section{DATA PROCESSING - TRANSPIRATION ESTIMATION}

In theory, it is assumed that, in the absence of intentionally applied heat, the tree xylem section being measured is uniform in temperature. Actually, that is not quite true. Two reasons could contribute for deviations to occur: an offset between $\mathrm{T}_{\text {upper }}\left[\mathrm{C}^{\circ}\right]$ and $\mathrm{T}_{\text {lower }}\left[\mathrm{C}^{\circ}\right]$ readings in equal ambient conditions and/or under natural temperature gradients (NTG). The first one can be caused by $\alpha$ and $\beta$ coefficients thermistors variability. The second concerns NTG, which may exist in plants growing in some environments. It is thus mandatory that thermistors offsets and NTG occurrences be detected and adjusted. After calibration the temperatures measurements are made individually with the heater OFF and $\mathrm{ON}$, being the captured values provided to the DPM module.

The process of calibration of temperature measurements in the tree trunk relies on the following algorithm:

1. Turn the heater off;

2. Measure both $\mathrm{T}_{\text {upper }}\left[\mathrm{C}^{\circ}\right]$ and $\mathrm{T}_{\text {lower }}\left[\mathrm{C}^{\circ}\right]$ temperatures during 15 minutes;

3. Compute the average offset $\left(\right.$ Bmean $\left.\left[{ }^{\circ} \mathrm{C}\right]\right)$;

4. Turn the heater on during 15 minutes;

5. Measure both Tupper $\left[\mathrm{C}^{\circ}\right]$ and Tlower $\left[\mathrm{C}^{\circ}\right]$ temperatures;

6. Calculate Tupadj $\left[\mathrm{C}^{\circ}\right]=$ Tupper $\left[\mathrm{C}^{\circ}\right]-\operatorname{Bmean}\left[{ }^{\circ} \mathrm{C}\right]$;

7. Calculate: $\Delta \mathrm{Tadj}=$ Tupadj $\left[\mathrm{C}^{\circ}\right]-$ Tlower $\left[\mathrm{C}^{\circ}\right]$

\section{RESULTS}

The results presented here concern the experimental evaluation of the sap flow measurements. 


\section{A. Laboratory experiments}

The results obtained in laboratory aimed at characterizing the temperature measurement probes. In order to evaluate the temperature measurement accuracy, in particular the offset, the $T_{\text {upper }}$ (heating capability not used) and $\mathrm{T}_{\text {lower }}$ probes, were inserted in a sponge with warm water. The temperature was measured during 4500 seconds. The water temperature was monitored with a reference thermometer. Figure 5 shows the evolution of the two measured temperatures. It can be seen that there is a good agreement between the two values, which differ with an average offset of approximately $0.09^{\circ} \mathrm{C}$ (Fig. 6).

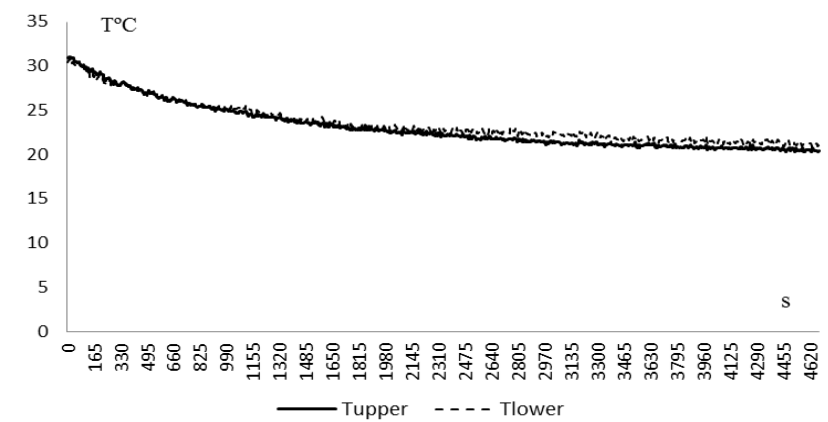

Fig.5 - Evolution of the temperatures provided by two tree probes.

Figure 7 shows the $T_{\text {upper }}$ and $T_{\text {lower }}$ temperatures obtained for the 6 made pairs of probes, with no calibration, in comparison to the temperature provided by a reference thermometer. It can be seen that the maximum obtained error is about $1{ }^{\circ} \mathrm{C}$. As the most important measurement is the difference of temperatures between probes in a pair and not the absolute temperature, each pair should be then calibrated by the algorithm, to obtain a minimum difference $\leq 0.2{ }^{\circ} \mathrm{C}$, according to the system resolution.

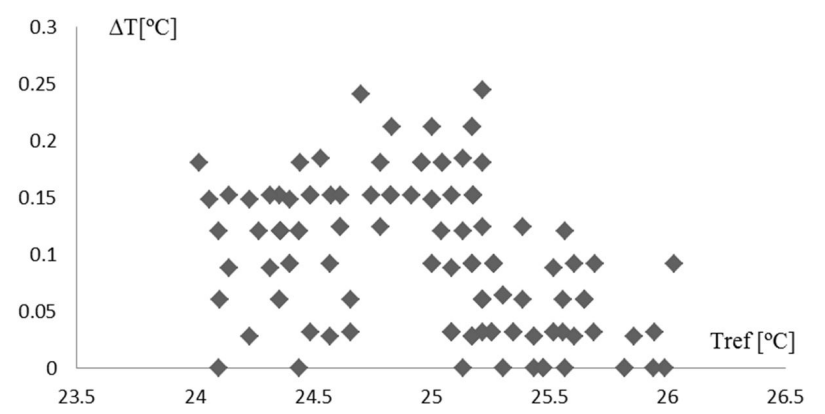

Fig. 6 - Distribution of the relative error obtained when measuring the same temperature with $\mathrm{T}_{\text {upper }}$ and $\mathrm{T}_{\text {lower }}$.

To evaluate the capability of heating a confined environment and detecting the heat convection, the $\mathrm{T}_{\text {upper }}$ and $\mathrm{T}_{\text {lower }}$ probes were inserted into a sealed tube previously filled with moist sandy soil.

The experiment consisted of activating the heater and regulating its temperature $\left(\mathrm{T}_{\text {upper }}\right)$ around $26{ }^{\circ} \mathrm{C}$ and acquiring the two ( $\mathrm{T}_{\text {upper }}$ and $\left.\mathrm{T}_{\text {lower }}\right)$ temperature measurements for 12 hours. Figure 8 shows the evolution of the applied power and temperatures measured. After one hour with the heater switched-on, its temperature was regulated with an on/off controlling process. During this period the two temperatures increased and then were maintained at an approximately constant temperature with a difference between the two of about $5^{\circ} \mathrm{C}$. The power was regulated around $0.15 \mathrm{~W}$.

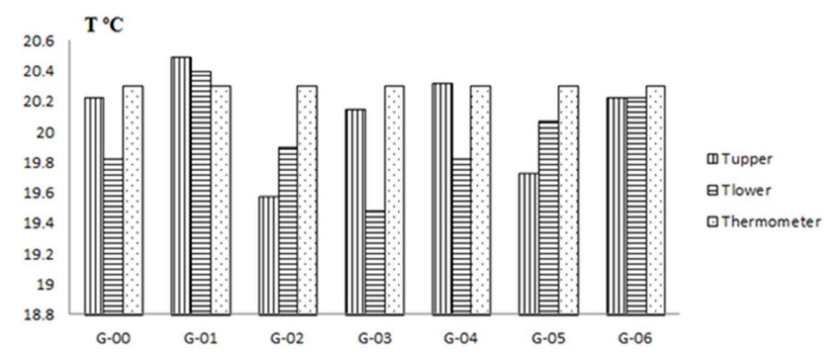

Fig. 7 - Distribution of the relative error obtained when measuring the same temperature with $\mathrm{T}_{\text {upper }}$ and $\mathrm{T}_{\text {lower }}$.

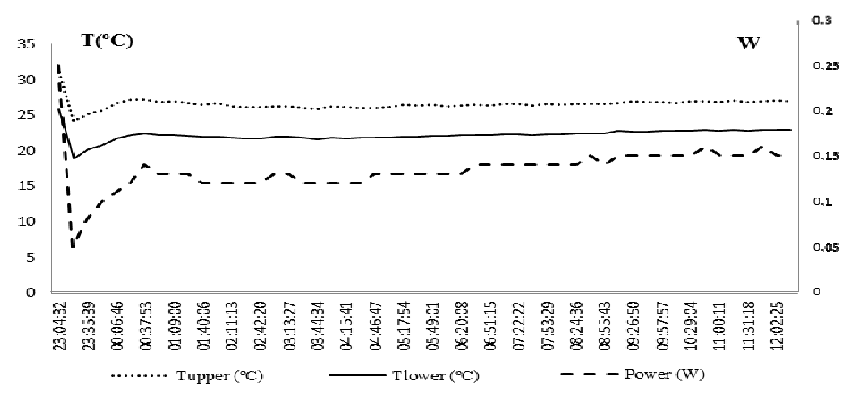

Fig. 8 - Evolution of the power applied with the HTS probe $\left(\mathrm{T}_{\text {upper }}\right)$ and temperatures measured with the two tree probes $\left(T_{\text {upper }}\right.$ and $\mathrm{T}_{\text {lower }}$ ).

\section{B. Field experiments}

The field experiments aimed at evaluating the heating capacity of probes when inserted into the tree and the sap flow algorithm mentioned in the section $\mathrm{V}$.

The 6 pairs of probes presented in Fig. 7 were installed in a kiwifruit orchard and data was captured during 10 days. Temperature measurements were acquired with the heater switched on for 15 minutes and likewise, with heater switched off for another 15 minutes. The averages of the temperatures provided by all $\mathrm{T}_{\text {lower }}$ probes ranged between $21{ }^{\circ} \mathrm{C}$ and $23{ }^{\circ} \mathrm{C}$. During 12 hours in continued measurements, the overall average temperature was $22.22^{\circ} \mathrm{C}$ $\pm 0.68^{\circ} \mathrm{C}$. It was observed that all heater probes correctly regulated the heating power around $0.18 \mathrm{~W}$, such as designed.

The heating capacity between $\mathrm{T}_{\text {upper }}$ probes has provided around $7{ }^{\circ} \mathrm{C}$ temperature increases. It could be confirmed that the heating operated as expected.

Figure 9 shows the evolution of the difference of temperatures captured, before $(\Delta \mathrm{T})$ and after $(\Delta \mathrm{T} \alpha)$ offset 
correction. The square wave form results from switching on $(\Delta \mathrm{T} \neq 0)$ and off $(\Delta \mathrm{T}=0)$ the heater.

It can be seen that after offset correction the differences observed with the heater off are reduced to $0^{\circ} \mathrm{C}$. The cyclic $\mathrm{ON} / \mathrm{OFF}$ heating included in the algorithm contributes to adjust the thermistor offset and the possible NTG's occurrences.

a)

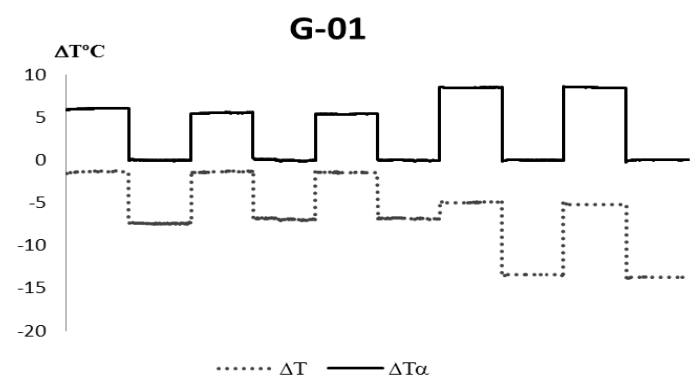

b)

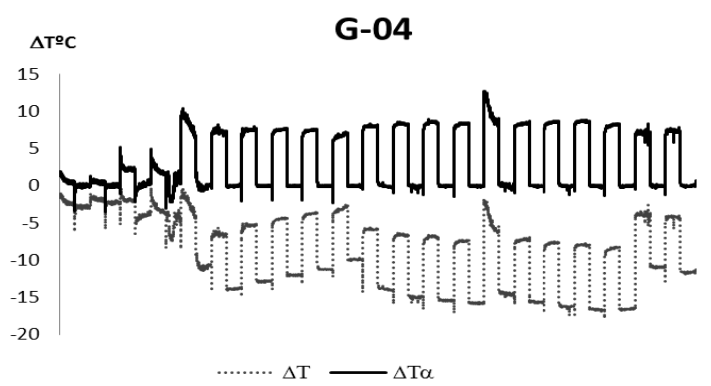

Fig.9 - Temperature measurements for sap flow estimation before $(\Delta \mathrm{T})$ and after $(\Delta \mathrm{T} \alpha)$ offset correction. a) G-01 probes , b) G-04 probes.

\section{CONCLUSIONS}

A smart orchard irrigation system (SOIS) based on a fuzzy inference control of the trees and soil evapotranspiration and soil conductivity is being developed.

The work presented here describes the underlying physical phenomena and the architecture of the application specific heaters, sensors and data acquisition system used to measure temperature differences which are on the basis of the estimation of the evapotranspiration process.

Experimental characterization results are presented which show that a precision of $0.2{ }^{\circ} \mathrm{C}$, in agreement with that required by applications of this nature, is obtained.

Preliminary results obtained in the field showed that it is able to fix the offset thermistor and NTG occurrences by the sap flow algorithm. Moreover, the SOIS probes demonstrated to be able to measure the temperatures in the trees and elevate the temperature above $7^{\circ} \mathrm{C}$ when the heater is $\mathrm{ON}$.
The probes and input/output board were custom made for this application in order to obtain cheaper and more flexible devices for the SOIS system under development.

\section{ACKNOWLEDGMENT}

This work is being supported by CAPES Foundation Ministry of Education of Brazil CSF Program. The authors also thank: the technical support provided by Eng. Pedro Alves - Department of Electrical and Computer Engineering of FEUP, Foundation for Science and Technology, Portugal (grant SFRH/BPD/100718/2014).

\section{REFERENCES}

[1] Allen, R. G. \& Pereira, L. S., "Estimating crop coefficients from fraction of ground cover and height", Irrigation Science, 28(1), pp 17 34, 2009.

[2] Allen, R., Pereira, L., Raes, D. \& M, S., Crop, Evapotranspiration. Guidelines for Computing Crop Water Requirements, (FAO, Ed) Irrig. and., p 300, 1998.

[3] Dias, N. S. N., Lima, F. A., Silva, C. R., Neto, S., Nogueira, O. \& Gheyi, H. R., "Use of reject brine from desalination on different development stages of hydroponic lettuce", Revista Caatinga, 24(1), pp 76-81, 2010.

[4] Forsythe, W. E., Smithsonian physical tables, Smithsonian (4169, I. P., Ed) Washington, DC, 1964.

[5] Gardner, H. \& Hanks, R., "Evaluation of the evaporation zone in soil by measurement of heat flux", Soil Science Society of America Journal, 30(4), pp 425-428, 1966.

[6] Granier, A., "Une nouvelle methode pour la measure du flux de seve brute dans le tronc des arbres", Annales des Sciences Forestieres, 42(2), pp 193-200, 1985.

[7] Heitman, J. L., Horton, R., Sauer, T. J., Ren, T. S. \& Xiao, X., "Latent heat in soil heat flux measurements" Agricultural and Forest Meteorology, 150(7-8), pp 1147-1153, 2010.

[8] MEGA 2560 Arduino.(2014) (arduino.cc). http://arduino.cc/en/Main/ arduinoBoardMega2560.

[9] Mayocchi, C. \& Bristow, K. (1995). Soil surface heat flux: some general questions and comments on measurements. Agricultural and Forest Meteorology.

[10] Mortensen, A. P., Hopmans, J. W., Mori, Y. \& Šimůnek, J., "Multifunctional heat pulse probe measurements of coupled vadose zone flow and transport", Advances in Water Resources, 29(2), pp 250-267, 2006.

[11] Paço, T., Ferreira, M., Rosa, R. D., Paredes, P., Rodrigues, G., Conceição, N., Pacheco, C. \& Pereira, L, "The dual crop coefficient approach using a density factor to simulate the evapotranspiration of a peach orchard: SIMDualKc model versus eddy covariance measurements", Irrigation Science, 30(2), pp 115-126, 2012.

[12] Pereira, L. S., Cordery, I. \& Iacovides, I., Coping with Water Scarcity, Addressing the Challenges, Dordrecht: Springer, cdc.gov p. 3822009.

[13] Pereira, L. S., Oweis, T. \& Zairi, A., "Irrigation management under water scarcity", Agricultural Water Management, 57(3), pp 175-206, 2002.

[14] Richards, L. A., Brown, J. W., Hayward, H. E., Richards, A., Bernstein, L., Hatcher, J. T. \& Reeve, R. C. Diagnosis and Improvement of Saline and Alkali Soils, Handbook, United States Department of Agriculture, Washington, D.C. USA, 1954.

[15] Siqueira, J. M., Paço, T. A., Silvestre, J. C., Santos, F. L., Falcão, A. O. \& Pereira, L. S. "Generating fuzzy rules by learning from olive tree transpiration measurement - An algorithm to automatize Granier sap flow data analysis" Computers and Electronics in Agriculture, 101, pp $1-10,2014$ 